\title{
Aldosterone secretion by the rat adrenal cortex is stimulated by the activation of protease-activated receptor 1
}

\author{
P W Raven, S Kapas ${ }^{1}$, M Carroll ${ }^{2}$ and J P Hinson ${ }^{2}$ \\ Department of Psychiatry and Behavioural Sciences, Royal Free and University College Medical School, UCL, Royal Free Campus, Rowland Hill Street, \\ London NW3 2PF, UK \\ ${ }^{1}$ Clinical Sciences Research Centre, St Bartholomew's and the Royal London School of Medicine and Dentistry, Queen Mary and Westfield College, \\ 2 Newark Street, London E1 2AD, UK \\ ${ }^{2}$ Department of Endocrinology, St Bartholomew's and the Royal London School of Medicine and Dentistry, Queen Mary and Westfield College, \\ Mile End Road, London E1 4NS, UK \\ (Requests for offprints should be addressed to J P Hinson, Department of Endocrinology, St Bartholomew's and the Royal London School of Medicine and \\ Dentistry, Queen Mary, University of London, Dominion House, Bartholomew Close, London EC1M 7BE, UK)
}

\begin{abstract}
Stimulation of aldosterone by a serine protease, trypsin, was first reported in 1982, although the mechanism of this effect was unclear. Recently, a family of protease-activated receptors (PARs) has been described and four members of the family characterised and cloned, including the previously recognised thrombin receptor. This study investigated whether PARs mediate the action of trypsin on aldosterone secretion. Using intact rat adrenal capsular tissue, thrombin was found to increase aldosterone secretion, and the effects of trypsin on aldosterone secretion were confirmed. Both trypsin and thrombin were shown to activate phospholipase $\mathrm{C}$, as measured by an increase in inositol triphosphate turnover by adrenal capsular tissue. It
\end{abstract}

was also shown that U73122, a phospholipase C inhibitor, attenuated the aldosterone response to trypsin. These effects were consistent with the activation of a PAR. Northern blot analysis revealed the presence of mRNA encoding PAR-1, but not PARs-2, -3 or -4 in the adrenal capsule/zona glomerulosa. Messenger RNA encoding PAR-1 was increased by dietary sodium depletion, consistent with previous reports of an increased response to trypsin after sodium depletion. These data suggest that the actions of trypsin on aldosterone secretion are mediated by PAR-1.

Journal of Endocrinology (2001) 169, 581-585

\section{Introduction}

The development of enzymatically dispersed cell suspensions in 1968 was a major step in the study of adrenocortical endocrinology, allowing steroidogenic responses to low concentrations of ACTH to be seen for the first time (Kloppenborg et al. 1968). However, in general these cell preparations did not respond well to angiotensin II, and it appeared that an element of the calcium signalling system was disrupted during the process of cell dispersal (Vinson et al. 1989). In the early days of work with adrenal cell suspensions, the dispersal methodology used either trypsin (Swallow \& Sayers 1969) or collagenase (Kloppenborg et al. 1968) as the digestive enzyme, but this was later replaced exclusively with collagenase, and adaptations of the method enabled the detection of considerably more sensitive responses to angiotensin II (Enyedi et al. 1981).

Studies from this laboratory demonstrated that proteolyic enzymes, including trypsin, were able to stimulate aldosterone secretion directly from intact rat adrenal capsular tissue (Raven et al. 1982, 1983a,b). This discovery challenged many assumptions that had previously been made about methods of tissue preparation, and the interpretation of physiologically relevant results (for review see Vinson et al. 1985). However, the mechanism of the effect of trypsin was unclear: it was believed either to break down possible steroid-protein complexes sequestered in the cell membrane, or to cause the transmembrane activation of steroidogenesis by a novel mechanism (Raven et al. 1982, Vinson et al. 1985). More recent studies revealed that trypsin activated protein kinase $\mathrm{C}$ in the adrenal zona glomerulosa (Vinson et al. 1990), although the possibility that trypsin may directly activate a phospholipase C-linked receptor was not considered a likely explanation of the effects seen.

Recently, a new family of G-protein coupled receptors has been described, termed protease-activated receptors (PARs), which include members of the thrombin receptor family (for review see Kawabata \& Kuroda 2000). To date, four members of this receptor family have been described, and the genes encoding them cloned. These receptors are activated by trypsin and by thrombin (Kawabata \& Kuroda 
2000). In the light of the previous findings it was deemed worthwhile to determine whether activation of a PAR may explain the effects of trypsin on aldosterone secretion.

In order to establish that trypsin stimulation of aldosterone secretion is mediated by a member of this receptor family, it is necessary to establish that: a) the adrenal cortex expresses the gene encoding the receptor, b) thrombin mimics the effects of trypsin, and c) the effect is associated with an increase in inositol triphosphate $\left(\mathrm{IP}_{3}\right)$, as all members of the PAR family are $\mathrm{G}_{\mathrm{q}}$ linked. In addition, as the actions of trypsin are greatly enhanced by dietary sodium restriction (McAuley et al. 1985b), this procedure should also be shown to increase receptor expression. The present study was designed to address these questions and determine whether a member of the PAR family mediates the actions of trypsin on the rat adrenal zona glomerulosa.

\section{Materials and Methods}

All chemicals were of analytical grade and obtained from Sigma Aldrich or Merck-BDH, Poole, Dorset, UK, with the following exceptions. All radiolabels were obtained from Amersham International plc, Amersham, Bucks, UK. AG1-X8 resin anion-exchange columns were obtained from Bio-Rad Laboratories, Hemel Hempstead, Herts, UK. ACTH(1-24) (Synacthen) was from Ciba-Geigy, Horsham, W Sussex, UK. The phospholipase C inhibitor, U73122, was from Calbiochem, Nottingham, Notts, UK.

Male and female Wistar rats (250-400 g body weight) were obtained either from A Tuck and Sons, Battlesbridge, Essex, UK or from the colony maintained at Queen Mary and Westfield College. Animals were maintained on normal rat chow, except for the dietary sodium restriction experiments, for which groups of animals were maintained for 21 days on a diet with fixed low $(4 \mathrm{mmol} /$ $\mathrm{kg})$ or normal $(174 \mathrm{mmol} / \mathrm{kg})$ sodium concentrations (Hinson \& Kapas 1995).

The rats were stunned and then killed by cervical dislocation, in accordance with Home Office regulations. Adrenals were rapidly removed and cleaned of adhering fat. Capsule fractions (with zona glomerulosa cells attached) were separated from inner adrenocortical tissue by pressure between glass plates. Capsules were preincubated in Krebs Ringer bicarbonate containing glucose $(2 \mathrm{mg} /$ $\mathrm{ml})(\mathrm{KRBG})$ for $1 \mathrm{~h}$ at $37{ }^{\circ} \mathrm{C}$ under an atmosphere of $95 \% \mathrm{O}_{2}-5 \% \mathrm{CO}_{2}$. After preincubation, capsules were incubated in fresh KRBG for $1 \mathrm{~h}$ under an atmosphere of $95 \% \mathrm{O}_{2}-5 \% \mathrm{CO}_{2}$ in the absence or presence of stimulants or inhibitors. The maximal concentrations of protease enzyme used were chosen to approximate those used in previous studies (1 mg/ml; Raven et al. 1982).

After incubation the capsules were discarded and the incubation media were placed into clean glass test tubes and heated at $100{ }^{\circ} \mathrm{C}$ for 20 min to destroy the proteolyic activity of the enzymes used. Aliquots of the media were cooled and transferred to microfuge tubes, which were stored at $-20{ }^{\circ} \mathrm{C}$ until the media were assayed for aldosterone. Aldosterone was measured in an aliquot of unextracted incubation medium by direct radioimmunoassay (Kapas et al. 1992).

Adenylyl cyclase activity was measured by competitive radioligand binding, using a binding protein prepared from bovine adrenal glands, as described previously (Kapas et al. 1994). $\mathrm{IP}_{3}$ turnover was assessed using an adaptation of existing methods (Kapas et al. 1994), as follows. Briefly, rat adrenal capsules were obtained as described above. After $1 \mathrm{~h}$ of preincubation, the capsules were incubated in $3 \mathrm{ml}$ KRBG with $10 \mu \mathrm{Ci}$ myo- $\left[2-{ }^{3} \mathrm{H}\right]$ inositol for $4 \mathrm{~h}$. After incubation, capsules were washed twice with KRBG containing $10 \mathrm{mmol} / \mathrm{l}$ inositol and $10 \mathrm{mmol} / \mathrm{l} \mathrm{LiCl}$. Capsules were then individually placed in tubes containing $400 \mu \mathrm{l} \mathrm{KRBG}$ and preincubated for $10 \mathrm{~min}$, after which time the stimulants were added in $100 \mu \mathrm{l}$ and the content of the tubes mixed rapidly. After 3 min the reaction was terminated by the addition of ice-cold perchloric acid $(15 \% \mathrm{v} / \mathrm{v})$, the capsular tissue was removed, and the supernatant neutralised by the addition of $1.5 \mathrm{ml}$ Freon: trioctylamine $(1: 1 \mathrm{v} / \mathrm{v})$. The $\left[{ }^{3} \mathrm{H}\right] \mathrm{IP}_{3}$ was separated by anion-exchange chromatography, following established methods (Downes \& Michell 1981, Enyedi et al. 1985).

\section{$m R N A$ analysis}

Total tissue RNA was isolated by acid guanidium thiocyanate-phenol-chloroform extraction using RNAzol solution (Biogenesis, Poole, Dorset, UK) following the manufacturer's instructions. The purity and concentration of RNA were measured spectrophotometrically at $260 / 280 \mathrm{~nm}$. Five micrograms of total RNA were primed with $1.5 \mu \mathrm{g}$ oligo-d(T) $)_{12-18}$ and reverse transcribed by avian myeloblastosis reverse transcriptase using the FirstStrand cDNA synthesis kit (Life Technologies, Paisley, Renfrewshire, UK). PCR was carried out as described previously (Martinez et al. 2000). For mRNA analysis, $10 \mu \mathrm{g}$ total RNA was electrophoresed in a formaldehyde- $1 \%$ agarose gel and transferred to Hybond-N nylon membrane (Amersham). After fixation by u.v. crosslinking, the membrane was hybridised overnight at $42{ }^{\circ} \mathrm{C}$ with $\left[\alpha_{-}{ }^{32} \mathrm{P}\right]$-dCTP-labelled full-length probes for PARs- 1 to -4 .

\section{Statistical analysis}

Arithmetic means and S.E.M. values were calculated. One-way ANOVA was used to test whether trypsin or thrombin had a significant effect on basal (control) levels of aldosterone or $\mathrm{IP}_{3}$ release.

\section{Results}

Both trypsin and thrombin were found to stimulate aldosterone secretion by rat adrenal capsular tissue (Figs 1 


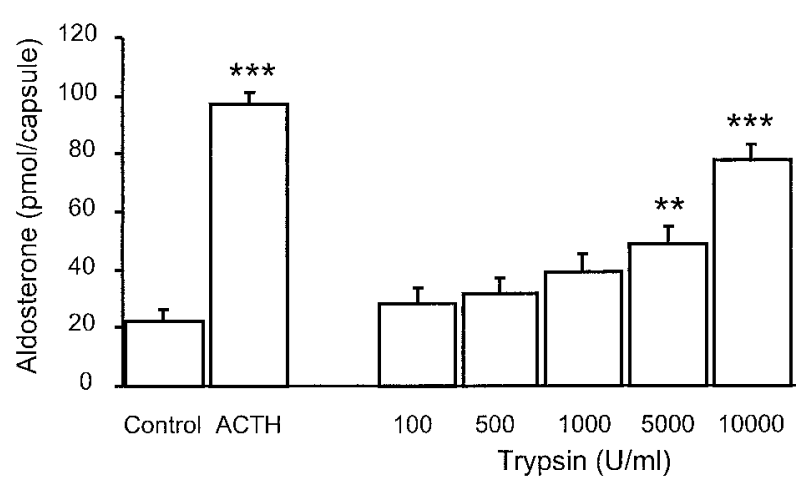

Figure 1 Effects of increasing concentrations of trypsin on release of aldosterone from intact adrenal capsular tissue (containing glomerulosa cells). ${ }^{* *} P<0 \cdot 01,{ }^{* * *} P<0 \cdot 001$ compared with control (ANOVA). ACTH (1 nmol/l) was included for comparison.

and 2). In the case of trypsin, a dose-related effect was seen, with a threshold of $5000 \mathrm{IU} / \mathrm{ml}$ and a maximal effect seen at $10000 \mathrm{IU} / \mathrm{ml}$. With thrombin a significant effect was only seen with the greatest concentration used, $50 \mathrm{IU} / \mathrm{ml}$. Neither thrombin nor trypsin had any effect on release of cAMP by rat adrenal capsular tissue (data not shown). Both thrombin and trypsin stimulated $\mathrm{IP}_{3}$ turnover, to levels comparable to those seen with angiotensin II stimulation (Fig. 3). The phospholipase C inhibitor attenuated the aldosterone response to trypsin (Fig. 4), but did not affect basal secretion. Northern blot analysis of rat capsular/zona glomerulosa mRNA revealed the presence of mRNA encoding PAR-1, but not PARs $-2,-3$ or -4 (Fig. 5). Analysis of rat adrenal mRNA obtained from animals maintained on a low-, normal- or high-sodium diet revealed that the expression of PAR-1 was greatly increased in response to the low-sodium diet, and diminished in the group fed a high-sodium diet (Fig. 6).

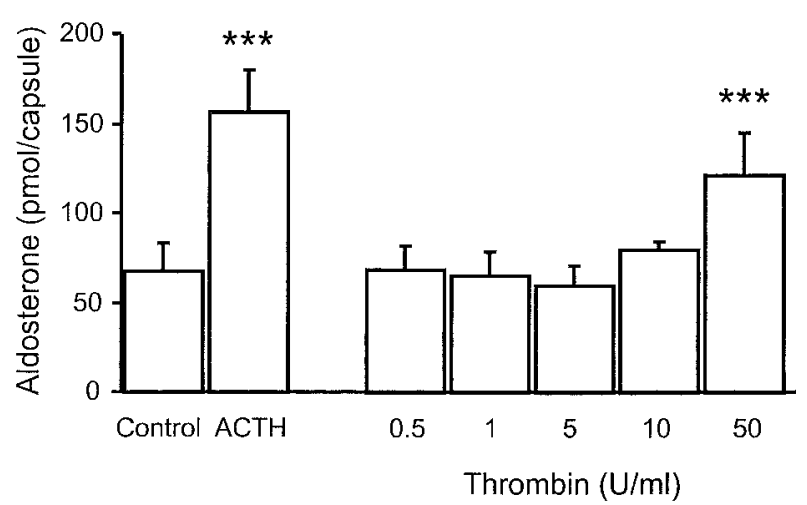

Figure 2 Effects of increasing concentrations of thrombin on release of aldosterone from intact adrenal capsular tissue (containing glomerulosa cells). ${ }^{* *} P<0.001$ compared with control (ANOVA). ACTH (1 nmol/l) was included for comparison.

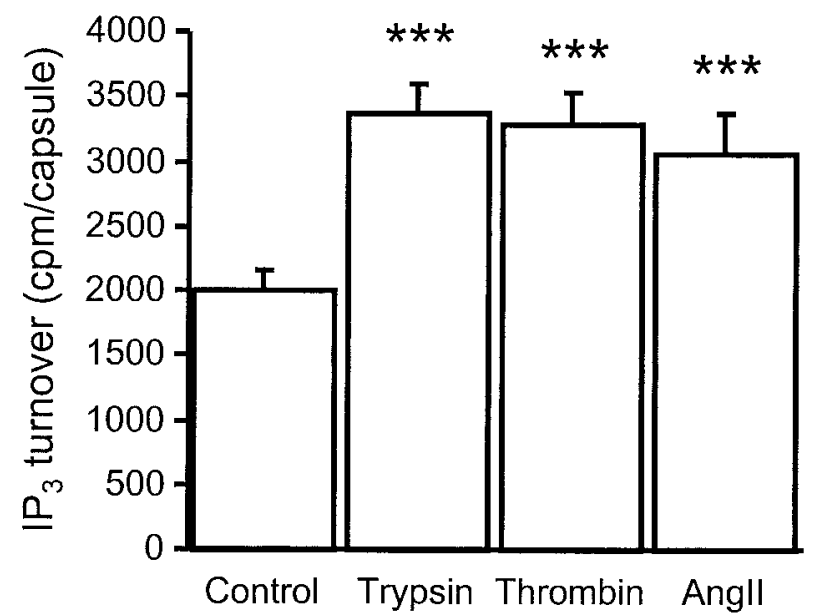

Figure 3 Effects of trypsin (10 $000 \mathrm{IU} / \mathrm{l})$, thrombin (50 IU/I) and angiotensin II (AngII) $(100 \mathrm{nmol} / \mathrm{l})$ on production of $\left[{ }^{3} \mathrm{H}\right] \mathrm{IP}$ by $\left[{ }^{3} \mathrm{H}\right]$ inositol-loaded adrenal capsular tissue. ${ }^{* * *} P<0 \cdot 001$ compared with control (ANOVA).

\section{Discussion}

This study demonstrates for the first time the expression of PAR-1 in the rat adrenal zona glomerulosa, and provides data that suggest that both thrombin and trypsin may activate this receptor and thereby stimulate aldosterone secretion. Previous studies in the early 1980s described the stimulatory effect of trypsin on aldosterone secretion, although no attempt was made to determine whether the effects were dose dependent. The present study confirms these findings and provides limited evidence for a dose dependency of the effect. A clear dose dependency may not be expected, however, as the activation of PARs by trypsin and thrombin is quite distinct from that of other G-protein coupled receptors, and is dependent upon their

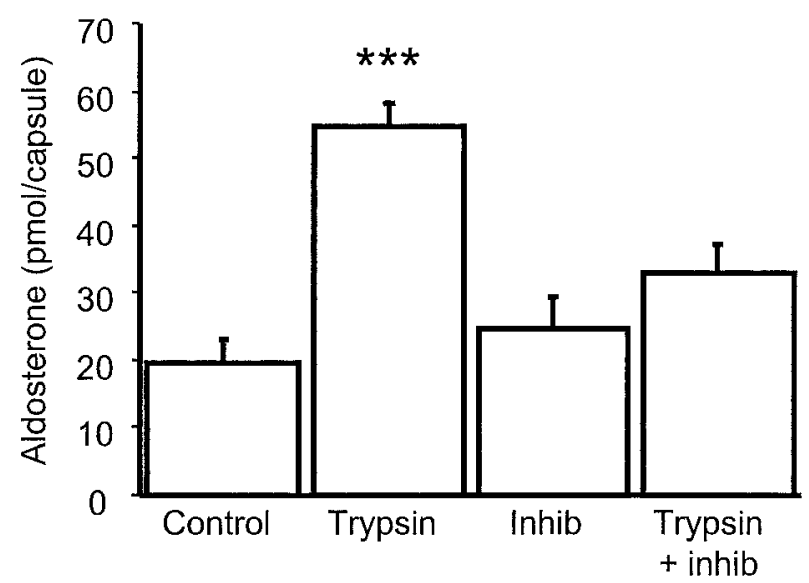

Figure 4 Effects of the phospholipase C inhibitor, U73122 $(10 \mu \mathrm{mol} / \mathrm{l})$, on basal and trypsin-stimulated release of aldosterone. $* * * P<0 \cdot 001$ compared with control (ANOVA). In the presence of inhibitor, trypsin did not significantly increase aldosterone secretion. 


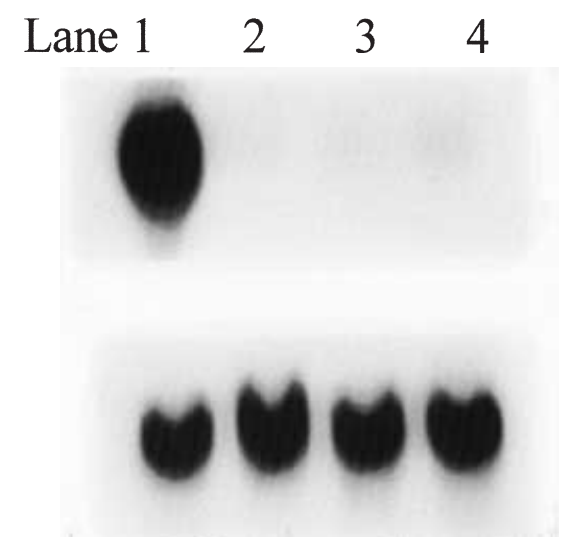

Figure 5 Northern blot analysis of rat adrenal zona glomerulosa mRNA reveals the presence of mRNA encoding PAR-1 (lane 1, top), but not PARs-2, -3 or -4 (lanes 2-4, top). The bottom lanes show GAPDH for comparison.

proteolytic action on the extracellular domain of the receptor (Kawabata \& Kuroda 2000), which may not be subject to the same kinetics as simple ligand-receptor interactions. In addition, the findings of the present study suggest that thrombin is also able to stimulate the release of aldosterone from rat adrenal capsular tissue. The finding of mRNA for PAR-1 in the zona glomerulosa is consistent with the possibility that PAR-1 mediates the actions of proteolytic agents on aldosterone secretion. This member of the PAR family of receptors is activated by both trypsin and thrombin (Altrogge \& Monard 2000) - an effect consistent with the present finding that both these enzymes stimulated the release of aldosterone. This is supported by the observation that $\mathrm{IP}_{3}$ turnover was enhanced by both trypsin and thrombin, as PAR-1 is known to be linked to $\mathrm{G}_{\mathrm{q}}$ activation and polyphosphoinositide turnover (Dery et al. 1998).

There are, at present, no specific antagonists available for the rat PAR-1 receptor. It is not possible to use a

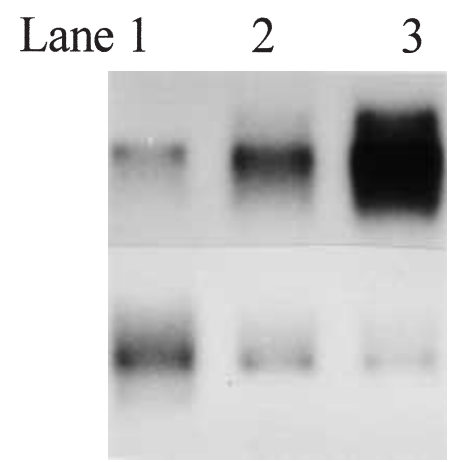

Figure 6 Northern blot analysis of mRNA to show the effects of dietary sodium restriction on the expression of PAR-1 by rat adrenal zona glomerulosa (top lanes). Lane 1: High-sodium diet; lane 2: normal diet; lane 3: low-sodium diet. Bottom lanes show GAPDH for comparison. trypsin inhibitor to check the specificity of the action of trypsin as these agents themselves have direct actions on adrenocortical steroid secretion (Pedersen \& Brownie 1983, McAuley et al. 1985a).

These studies also confirm a role for the calcium/ polyphosphoinositide signalling system in the adrenal response to trypsin and thrombin. Previous studies demonstrated a translocation of protein kinase $\mathrm{C}$ from cytosol to membrane fraction in the adrenal zona glomerulosa in response to trypsin, suggesting that trypsin may activate this intracellular pathway (Vinson et al. 1990). At that time it was not clear how trypsin achieved this effect, although it was postulated that trypsin may somehow directly activate phospholipase C (Vinson et al. 1990). The present findings confirm that trypsin increases $\mathrm{IP}_{3}$ turnover in the adrenal and, furthermore, present evidence that this effect may be mediated by the activation of a trypsin-sensitive receptor, as these receptors are $\mathrm{G}_{\mathrm{q}}$ linked (Dery et al. 1998). This suggestion is further supported by the finding that a phospholipase $\mathrm{C}$ inhibitor attenuated the aldosterone response to trypsin.

The finding of increased PAR-1 expression in response to dietary sodium restriction is consistent with a role for this receptor in the regulation of aldosterone secretion, and particularly the response of the adrenal to changes in sodium balance. Previous studies have shown that the aldosterone response to trypsin is greatly enhanced by prior sodium depletion (McAuley et al. 1985b). The results of the present study suggest that this effect may be mediated by increased expression of PAR- 1 in response to dietary sodium depletion.

The question of the physiological ligand for this receptor remains unclear, although several studies have demonstrated the production of both a trypsin-like protease (Evangelista et al. 1982, Lindberg et al. 1982) and other proteases (Roberts et al. 1992) by the adrenal gland. More recently, findings by Lowry's group have implicated a novel adrenal protease in the control of compensatory adrenal growth (Bicknell et al. 1998). It remains to be seen whether any endogenous adrenal protease can activate PAR-1 in the zona glomerulosa and thereby stimulate aldosterone secretion.

In conclusion, these data demonstrate that: a) mRNA encoding PAR-1 is present in the rat adrenal zona glomerulosa, suggesting that the PAR-1 receptor is present in this tissue; b) thrombin, like trypsin, is able to stimulate aldosterone secretion; c) the effects of both trypsin and thrombin are associated with an increase in $\mathrm{IP}_{3}$ turnover; d) dietary sodium restriction increases PAR-1 expression. Taken together, these findings make it clear that PAR-1 is likely to mediate the effects of trypsin on the rat adrenal cortex.

\section{Acknowledgement}

We are grateful to the Wellcome Trust for Project Grant support. 


\section{References}

Altrogge LM \& Monard D 2000 An assay for high-sensitivity detection of thrombin activity and determination of proteases activating or inactivating protease-activated receptors. Analytical Biochemistry 277 33-45.

Bicknell AB, Hutchinson EG, Lomthaisong K, Gladwell RRT \& Lowry PJ 1998 Three dimensional structure of an adrenal protease predicts substrate specificity and retention at site of secretion in compensatory growth. Journal of Endocrinology 159 (Suppl) OC31.

Dery O, Corvera CU, Stenhoff M \& Bunnett NW 1998 Proteinase activated receptors: novel mechanisms of signalling by serine proteases. American Journal of Physiology 274 C1429-C1452.

Downes CP \& Michell RH 1981 The polyphosphoinositide phosphodiesterase of erythrocyte membranes. Biochemical Journal 198 133-140.

Enyedi P, Spät A \& Antoni FA 1981 Role of prostaglandins in the control of the function of adrenal glomerulosa cells. Journal of Endocrinology 91 427-437.

Enyedi P, Büki B, Mucsi I \& Spät A 1985 Polyphosphoinositide metabolism in adrenal glomerulosa cells. Molecular and Cellular Endocrinology 41 105-112.

Evangelista R, Ray P \& Lewis RV 1982 A 'trypsin-like' enzyme in adrenal chromaffin granules: a proenkephalin-processing enzyme. Biochemical and Biophysical Research Communications 106 895-902.

Hinson JP \& Kapas S 1995 Effects of sodium depletion on the response of rat adrenal zona glomerulosa cells to stimulation by neuropeptides: actions of vasoactive intestinal peptide, enkephalin, substance $\mathrm{P}$, neuropeptide $\mathrm{Y}$ and corticotropin releasing hormone. Journal of Endocrinology 146 209-214.

Kapas S, Orford CD, Barker S, Vinson GP \& Hinson JP 1992 Studies on the intracellular mechanism of action of $\alpha$-melanocyte-stimulating hormone $(\alpha-\mathrm{MSH})$ on rat adrenal zona glomerulosa. Journal of Molecular Endocrinology 9 47-54.

Kapas S, Purbrick A, Vinson GP \& Hinson JP $1994 \alpha$-MSH-induced inhibition of AII-receptor mediated events in the rat adrenal zona glomerulosa. Journal of Molecular Endocrinology 13 95-104.

Kawabata A \& Kuroda R 2000 Protease-activated receptor (PAR), a novel family of G-protein-coupled seven transmembrane domain receptor: activation mechanisms and physiological roles. Japanese Journal of Pharmacology 82 171-174.

Kloppenborg PWC, Island DP, Liddle GW, Michelakis AM \& Nicholson WE 1968 A method of preparing adrenal cell suspensions and its applicability to the in vitro study of adrenal metabolism. Endocrinology 82 1053-1058.

Lindberg I, Yang HYT \& Costa E 1982 Characterisation of a partially-purified trypsin-like enkephalin-generating enzyme in bovine adrenal medulla. Life Sciences 31 1713-1716.

McAuley ME, Raven PW \& Vinson GP 1985a Effects of protease inhibitors on adenylate cyclase activation and aldosterone production in rat adrenal zona glomerulosa cells. Cell Biochemistry and Function 3 277-281.
McAuley ME, Vinson GP, Raven PW, Abayasekara DRE \& Whitehouse BJ 1985b Factors affecting the trypsin-induced release of aldosterone in rat adrenal zona glomerulosa tissue. Journal of Steroid Biochemistry 23 219-222.

Martínez A, Kapas S, Miller M-J, Ward Y \& Cuttitta F 2000 Coexpression of receptors for adrenomedullin, calcitonin generelated peptide and amylin in pancreatic beta cells. Endocrinology 141 401-411.

Pedersen RC \& Brownie AC 1983 ACTH stimulation of adrenal steroidogenesis is sensitive to trypsin inhibitors. Endocrinology 112 1550-1552.

Raven PW, McCredie E, Vinson GP, Goddard C \& Whitehouse BJ 1982 Effects of proteolytic enzymes on steroid release from rat adrenal zona glomerulosa tissue: evidence for novel steroid-protein complexes. Biochemical and Biophysical Research Communications 104 1247-1254.

Raven PW, McCredie E, McAuley M \& Vinson GP 1983a Origins of the differences in function of rat adrenal zona glomerulosa cells incubated as intact tissue and as collagenase-prepared cell suspensions. Cell Biochemistry and Function 1 117-124.

Raven PW, McAuley ME \& Vinson GP 1983b Serine proteases selectively control the output of 18-hydroxycorticosterone and aldosterone in stimulated zona glomerulosa tissue of the rat. Journal of Endocrinology 99 13-22.

Roberts SF, Irvine JW \& Lindberg I 1992 Characterisation of proenkephalin-cleaving proteinases in bovine adrenal chromaffin granules using [S-35] proenkephalin copolymerised into sodium dodecyl sulfate-polyacrylamine gel-electrophoresis. Journal of Neurochemistry 58 593-599.

Swallow RL \& Sayers G 1969 A technique for the preparation of isolated rat adrenal cells. Proceedings of the Society for Experimental Biology and Medicine 131 1-4.

Vinson GP, Hinson JP \& Raven PW 1985 The relationship between tissue preparation and function; methods for the study of control of aldosterone secretion: a review. Cell Biochemistry and Function 3 235-253.

Vinson GP, Laird SM, Whitehouse BJ \& Hinson JP 1989 Specific effects of agonists of the calcium messenger system on secretion of 'late pathway' steroid products by intact tissue and dispersed cells of the rat adrenal zona glomerulosa. Journal of Molecular Endocrinology 2 157-165.

Vinson GP, Laird SM, Hinson JP, Mallick N, Marsigliante S \& Teja R 1990 Trypsin stimulation of aldosterone and 18-hydroxycorticosterone production by rat adrenal zona glomerulosa tissue is mediated by protein kinase C activation. Journal of Molecular Endocrinology 5 83-95.

Received in final form 30 January 2001 Accepted 8 February 2001 